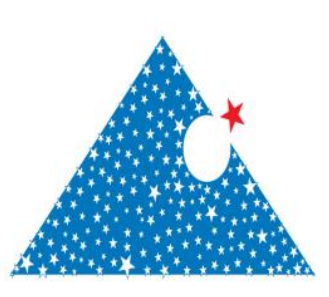

\title{
Yanlı Oransal Seyrüsefer ile İnsansız Hava Araçları için Yörünge Takibi
}

\author{
Raziye TEKIN $^{1 a^{*}}$, Koray Savaş ERER ${ }^{1 \mathrm{~b}}$ \\ ${ }^{1}$ Roketsan A.Ş., 06780, Elmadağ Ankara TÜRKIYY \\ razytekin@gmail.com
}

Received/Geliş: 04.05.2020

Accepted/Kabul: 17.09.2020

Öz: İnsansız hava araçları için yörünge takibine yönelik, geometrik yöntemleri temel alan füze güdümü alanından bir çözüm önerilmiştir. Bu çözüm yanlı saf oransal seyrüsefer olarak da tanımlanan bir yöntemdir. Sanal hedef konsepti kullanılarak yörünge takip problemi, bir kuyruk takibi problemine dönüştürülmüştür. Sanal hedefin yörünge üzerinde hareket etmesi ve takipçinin de sanal hedefi kuyruk takibine almasıyla, yörünge takibi elde edilmiştir. Sanal hedefin hızı, takipçiye olan mesafesi ile tasarımcı tarafından belirlenen sabit bir kuyruk takip mesafesinin oranına bağlıdır. Güdüm kanunu için bir seyrüsefer sabiti seçilmesi ve bir de yanlılık terimi tasarlanması gerekmektedir. Bahsi geçen yanlılık terimi, çarpma açısı ve kuyruk takibi problemlerinin benzerliği kullanılarak bulunur. Numerik benzetim çalışmaları düz ve eğri olmak üzere iki yörünge üzerinde gösterilmiştir. Farklı seyrüsefer sabitlerinin ve tasarımcının belirlediği kuyruk takip mesafesinin, takip performansı üzerindeki etkisi tartış1lmıştır.

Anahtar Kelimeler: Yörünge takibi, füze güdümü, sanal hedef, kuyruk takibi, oransal seyrüsefer

\section{Path Following for Unmanned Aerial Vehicles with Biased Proportional Navigation}

\begin{abstract}
A solution for unmanned aerial vehicle path following is proposed based on a geometric method from the missile guidance field. This method is known as biased pure pursuit navigation. Using the virtual target concept, the path following problem is addressed as a tail chase missile engagement, where the virtual target travels on the predefined path. The speed of the virtual target depends on the ratio of the range between the vehicles and the user specified distance of pursuit. The guidance law has a navigation constant and a bias term to be determined. Using the analogy of the impact angle problem and the tail chase engagement, the bias term of the guidance law is designed. Numerical simulations that involve circular and straight paths are presented. The tracking performance that results from choosing different navigation constants and different pursuit distances ise discussed.
\end{abstract}

Keywords: Path following, missile guidance, virtual target, tail-chase, proportional navigation

\section{Giriş}

İnsansız hava araçlarında (İHA) artan yüksek seviye otonomi ihtiyacı, etkin yörünge takip algoritmalarını gerekli kılmıştır. Bu sistemler için, düz bir çizgi izleme probleminin çok daha ötesinde izlenmesi beklenen yörüngeler tanımlanmaktadır. Dolayısı ile hassas takip algoritmalarına duyulan gereksinim de artmıştır. Bu takip algoritmaları sadece insansız hava araçları ile sınırlı kalmayıp, robotlar ve füzeler için de elzemdir. Farklı uygulamalar için temelde aynı probleme ve kinematiğe dair çözümler geliştirilmektedir. Bu nedenle robotik alanındaki bir metodun İHA'lara uyarlandığını ya da füze güdümünde kullanılan yöntemlerin İHA ya da robotlara uygulandığı Bu makaleye atıf yapmak için

Tekin, R., Erer, K.S., “Yanlı Oransal Seyrüsefer ile Insansız Hava Araçları için Yörünge Takibi” El-Cezerî Fen ve Mühendislik Dergisi 2020, 7 (3); $1432-1439$. 
görülebilir [1-3]. Diğer bir deyişle, farklı alanlardaki ortak uygulamalar problemin çözümünü zenginleştirmektedir.

Bu çalışmada, füze güdümünde kuyruk takibi olarak bilinen bir uçuş şeklini sağlayacak bir güdüm algoritması tasarlanmıştır. Füzeyi hedefe doğrudan götürmeyen ve hedefe ulaşmanın yanında farklı isteklerin de karşılanmasını sağlayan bu tip algoritmalar, yörünge şekillendirme algoritmaları olarak da isimlendirilir [4]. Kuyruk takibi, füze ile hareketli hedefin aynı uçuş yoluna sahip olması ve böylece füzenin, uçuş boyunca hedefin arkasında hareket etmesi olarak tanımlanabilir. Bunun için saf oransal seyrüsefer güdüm algoritmasına bir yanlılık terimi eklenmiştir. Bu yanlılık terimi hedef ile takipçinin angajman açılarına bağlı olarak zamanla değişen bir parametredir. Kuyruk takibi altındaki hareketli hedefin yerini tutmak üzere sanal bir hedef oluşturulmuştur [5]. Böylelikle, zamana bağlı olmayan, önceden tanımlı bir yörünge üzerinde sanal hedef hareket ettirilir ve kuyruk takibi ile de yörünge takibi sağlanır.

İlerleyen bölümlerde önce literatür özeti, takibinde eşleşme kinematiği ve sonrasında sanal hedef tanımlaması anlatılacaktır. Daha sonra hareketli hedefe yönelik kuyruk takibi, füzelerdeki varış açısı kontrolü üzerinden tasarlanacaktır. Son olarak, bir insansız hava aracının istenen yörüngeyi takibi, benzetim ortamında oluşturularak performansı incelenecek ve yörünge takiplerinde kullanılan bir yöntem olan saf takip ile karşılaştırılacaktır.

\section{Literatür Özeti}

Yörünge takibi denildiğinde, literatürde yoğunlukla robotik ve insansız hava araçları alanlarında çalışmalar ile karşılaşılır. İnsansız hava araçlarında yörünge takibi için genel bir derleme çalışması olarak [6] incelenebilir. Bu çalışmada yörünge takibi ve gezinge takibi ayrımı yapılmıştır. Buna göre; yörünge takibinde (path following) yörünge zamana bağlı değilken, gezinge takibinde (trajectory tracking) gezinge zamanın bir fonksiyonu olarak tanımlanmıştır. Yörünge takibi için mevcut çalışmalar ilk olarak şöyle gruplandırılabilir: Lyapunov teorisini kullanarak geri adımlama (backstepping), doğrusal olmayan dinamik tersleme (nonlinear dynamic inversion) ve optimal kontrol yöntemleri ile yörünge takibi. Diğer grup ise bu makalenin de içinde olduğu geometrik yaklaşımları ve vektör alanları ile yörünge takibini içerir. İlk grup için [7-9] örnek olarak incelenebilir. [7]'de yörünge takibi problemi geri adımlama tekniği ile ele alınarak, bu tekniğin diğer kontrol yöntemlerine oranla daha geniş çözüm aralığı sunmasından dolayı daha iyi performans gösterdiği belirtilmiştir. [8] numaralı çalışmada, üç boyutta tekillik içermeyen bir çözüm, Lyapunov teorisi temelinde anlatılmaktadır. [9] ise geri besleme doğrusallaştırmasına bir örnektir. Tasarlanan kontrolcüde yörünge üzerindeki hız ve sapma açısı, yer değiştirmenin bir fonksiyonu olarak tanımlanmıştır.

İHA'lardaki ilk vektör alan uygulamalarından biri [10]'dur. Bu çalışmada düz ve eğri yörüngeler için örnekleme yapılmış ve yörünge takip hataları çeşitli bozucular altında incelenmiştir. [11]'de ise üç boyutlu yörünge takip problemi, hız vektör alanı tanımlamaları üzerinden çözülmüş ve takip için iç kontrolcü döngüleri de anlatılmıştır. Geometrik yöntemler ilk olarak füze güdüm ve kontrol literatüründe anlatılmıştır. Bu yöntemler havuç kovalama (carrot chasing), saf takip (pure pursuit) ve yörünge şekillendirme (trajectory shaping) olarak karşımıza çıkmaktadır. Bunlar daha sonra insansız diğer araçlarda uygulama alanı bulmuştur. [1,2,13] numaralı çalışmalarda, saf takip yönteminin yörünge takibine nasıl uygulandığı görülebilir. [12]'de havuç kovalama yöntemi, sanal hedef takibi ile uygulanmıştır. Yörünge şekillendirme ise çarpma açısı kontrolü üzerinden [3]'te anlatılmış ve saf takip ile performans karşılaştırması yapılmıştır. 


\section{Eşleşme Kinematiği}

Bir takipçi ile sanal hedef arasındaki geometrik ilişki Şekil 1'de gösterilmiştir. $r$, takipçinin hedefe olan uzaklığını yani menzili ve $a$, yanal ivmesini temsil eder. $v$ hız, $\gamma$ uçuş yörünge açısı, $\lambda$ görüş hattı açısıdır. Takipçi için hız vektörünün dönüş hızı ile maruz kalınan ivme arasında $a=v_{T}$ \& ilişkisi vardır.

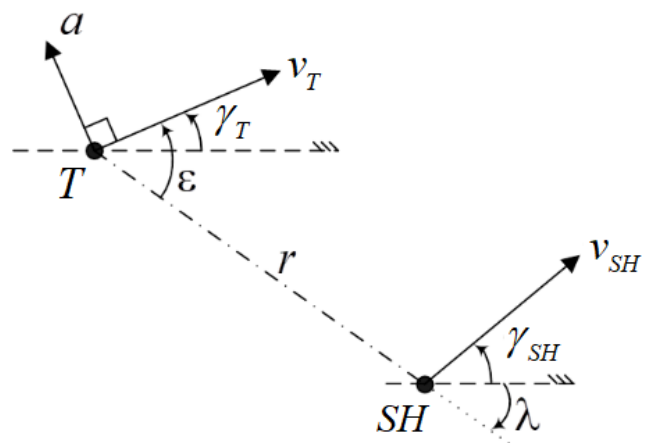

Şekil 1. Eşleşme kinematiği

$\mathrm{Bu}$ eşleşme kinematiğini iki diferansiyel denklem ile ifade etmek mümkündür. Bunlardan ilki menzilin değişimini tarif eden denklemdir:

$$
\&=-v_{T} \cos \varepsilon+v_{S H} \cos \left(\lambda-\gamma_{S H}\right)
$$

Diğeri, görüş hattı açısal hızının değişimini ifade eder:

$$
r \&=-v_{T} \sin \varepsilon+v_{S H} \sin \left(\lambda-\gamma_{S H}\right)
$$

Şekil 1'deki $\varepsilon$ ise füze hız vektörü ile görüş hattı arasındaki açı olup bakma açısı olarak ifade edilir. Diğer açılarla arasındaki ilişki şu şekildedir:

$$
\varepsilon=\gamma_{T}-\lambda
$$

\section{Sanal Hedef Takibi}

Geometrik yöntemlerinin yörünge takibi amacıyla kullanıldığ çalışmalarda sıklıkla başvurulan bir yöntem, bir sanal hedef tanımlanmasıdır. Bu sanal hedef, istenen yörünge üzerinde belirli bir hızla ilerler. Şekil 2'de gösterildiği üzere takipçi, sanal hedefi kuyruk takip modunda izler ve böylece dolaylı olarak yörünge üzerinde ilerler. Böylece takip sağlanmış olur.

Sanal hedef, takipçi ile olan mesafesine göre hızını ayarlayarak, algoritma tarafından takip edilebilir bir konum oluşturur. Sanal hedefin hızı şu şekilde tanımlanır:

$$
v_{S H}=v_{T} \frac{r^{*}}{r}
$$

$r^{*}$, tasarımcı tarafından belirlenen sabit bir mesafedir. Diğer bir deyişle, kuyruk takibi yapılacak mesafedir. $r$ ise yukarıda belirtilmiş olduğu gibi takipçi ile sanal hedef arasındaki anlık mesafedir. Denklem 4'teki gösterildiği üzere, sanal hedefin hızı bu iki mesafenin oranına göre değişir [13]. 


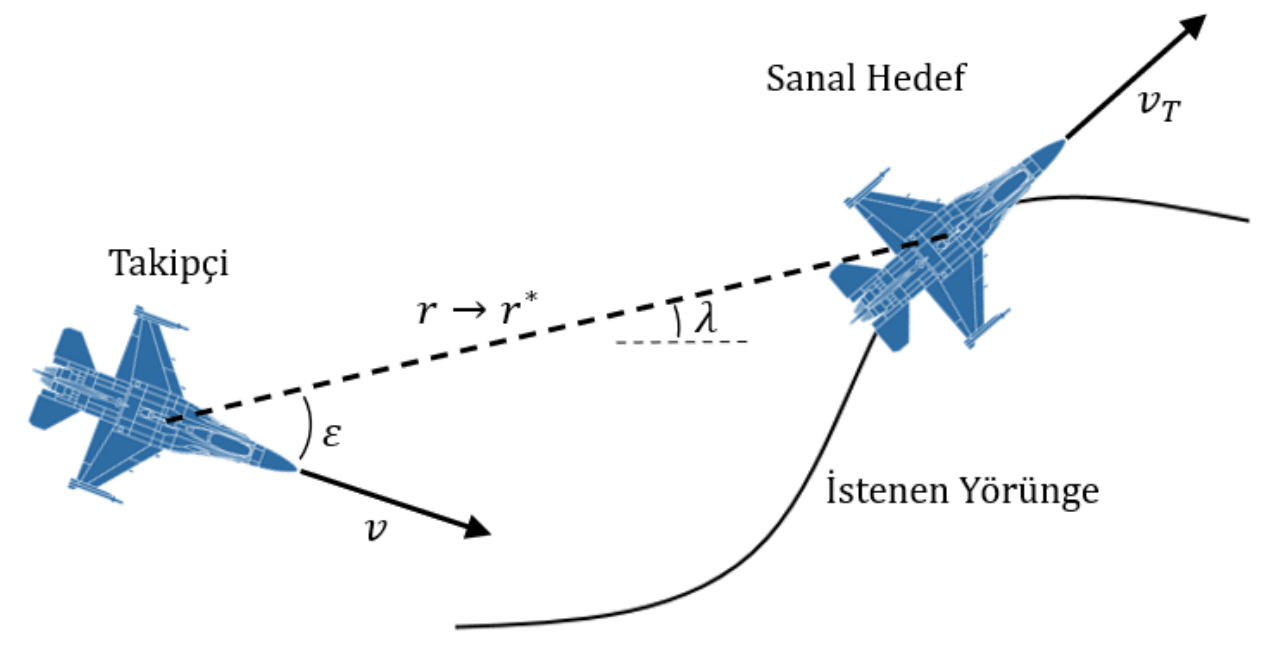

Şekil 2. Sanal hedef tanımlaması ile yörünge takibi

\section{Yörünge Takip Algoritması Tasarımı}

Yörünge takip algoritmalarında kullanılan sıklıkla kullanılan geometrik yöntemlerden biri, temelde bir füze güdüm algoritması olan saf oransal seyrüseferdir. Çoğunlukla sanal hedef takibi çerçevesinde kullanılır ve güdüm komutu şu şekildedir:

$$
\not=\not \&
$$

Havuç kovalama olarak da bilinen bu yöntemde, sanal hedef havuç olup, önceden belirlenmiş bir yörünge üzerinde hareket eder. Füzeler için bu, hareketli hedeflere karşı tanımlanan bir güdüm problemidir. Sanal hedefe karşı yapılan kuyruk takibinin amacı hedefi yakalamak değil, yukarıda bahsedildiği gibi belirli bir mesafeden takip etmektir.

Ancak bu yöntemin, özellikle yörünge eğrildiğinde, performans kaybına sebep olduğu bilinmektedir [3]. Çözüm olarak, saf oransal seyrüsefer güdüm kanununa $(\dot{\gamma}=N \dot{\lambda})$ bir yanlılık (bias), yani ek terim ilave etmek düşünülebilir [14]-[16]. Bu durumda güdüm komutu aşağıdaki gibi olacaktır:

$$
\not \&=N \& b
$$

Tasarımcı için bu denklem ile en az iki adet serbestlik sağlanmıştır. Bunlardan ilki, seyrüsefer güdüm kazancı olarak bilinen $N$ katsayısıdır. Diğeri ise tasarlanması gereken $b$ değeridir. Şekil 2'den anlaşılabileceği gibi, hareketli bir hedefe kuyruk takibi yapıldığında takipçinin ve hedefin hız vektörlerinin her ikisi de görüş hattının üzerinde olacaktır. $t^{*}$ ile işaret edilen an, füzenin kuyruk takibine ulaştığı an olup, bu koşulda $\gamma_{T}^{*}=\lambda^{*}=\gamma_{S H}$ eşitliği geçerli olur. Kuyruk takibi esas olarak, hedefin yörünge açısının takibi olduğu için çarpma açısı kontrolü yöntemlerini akla getirir ki [3]'te bu yöntemlerden biri yörünge takibi için önerilmiştir. Dolayısı ile $b$ değerinin tasarımı çarpma açısı kontrolü üzerinden yapılacaktır.

Öncelikle anlık yörünge açısına ulaşmak için Denklem 6' daki güdüm komutunun integrali alınırsa

$$
\gamma_{T}=\gamma_{T, 0}+N\left(\lambda-\lambda_{0}\right)+\int_{t_{0}}^{t} b \mathrm{~d} t
$$


eşitliğine ulaşılır. Burada 0 ilk andaki değerleri işaret eder. Çarpma anında $\gamma_{T}^{*}=\lambda^{*}$ olacağından, çarpma açısı denklemi aşağıdaki gibi yazılabilir:

$$
\gamma_{T}^{*}=\frac{N \lambda_{0}-\gamma_{T, 0}-\int_{t_{0}}^{t^{*}} b \mathrm{~d} t}{N-1}
$$

Eğer $b$ 'nin sabit bir değer olduğu varsayılırsa, istenen çarpma açısı için ne kadar zaman geçmesi gerektiği hesaplanabilir. Lakin, burada ilgilendiğimiz husus hedefin bir açı ile yakalanması değil, sanal hedefin kuyruk takibidir. Bu nedenle, hemen yukarıda değinilen $\gamma_{T}^{*}=\gamma_{S H}$ eşitliği kullanılarak $b$ değerinin bulunması için Denklem 8 yeniden düzenlenirse

$$
b=\frac{N \lambda_{0}-\gamma_{T, 0}-(N-1) \gamma_{S H}}{T}
$$

Burada $T$, toplam angajman süresidir. Kaba bir yaklaşımla bu süre şöyle ifade edilebilir:

$$
T=\frac{r_{0}}{v_{T}}
$$

Yörüngenin değişkenliği göz önüne alınırsa, sabit bir $b$ değeri yerine anlık olarak değişen bir değer ile devam etmek gereklidir. Bu nedenle Denklem 9' daki ilk değerler yerine anlık değerler alınırsa, $b$ değeri şu şekilde olur:

$$
b=\frac{N \lambda-\gamma_{T}-(N-1) \gamma_{S H}}{r / v_{T}}
$$

Böylece güdüm tasarımı tamamlanmış olur. Nihai güdüm kanunu, Denklem 6'da Denklem 11'in kullanılması ile aşağıdaki gibi elde edilir:

$$
\notin=N \& \frac{N \lambda-\gamma_{T}-(N-1) \gamma_{S H}}{r / v_{T}}
$$

\section{Benzetimler}

Önerilen yörünge takip algoritmasının performansı iki ayrı grupta incelenmiştir. Öncelikle, düz bir yörüngeye farklı güdüm katsayıları altında yakınsama davranışı incelenmiştir. Bu benzetim çalışmasında, sanal hedefin hızı ile takipçi füzenin hızı aynıdır. Diğer bir deyişle, Denklem 4'teki menziller oranı 1 olarak tutulmuştur. Buradaki amaç, eğer yapılan güdümde takip mesafesi ile tasarımcı tarafından belirlenen $r_{\text {takip }}$ oranının bir olduğu durumda, $r_{\text {takip }}$ 'in düz yörüngede nasıl bir davranış izleyeceğini incelemektir. Sonrasında, eğri bir yörüngeyi takip başarısı farklı $r^{*}$ değerleri altında incelenmiştir. Bunlara ilaveten Denklem 5'teki saf takip algoritması ile de karşılaştırma yapılmıştır. Benzetimler ideal koşullar altında koşturulmuştur. Takipçinin hızı $100 \mathrm{~m} / \mathrm{s}$ olup sabittir.

\subsection{Farklı $N$ Değerleri Altında Performans İncelemesi}

$\mathrm{Bu}$ incelemede, güdüm katsayısının değişiminin sistem performansı üzerindeki etkisi incelenmiştir. Sanal hedef takibinde, Denklem 4 kullanılmamıştır ve sanal hedefin hızı takipçi ile aynıdır. $N$ değerleri $0.5,1$ ve 2 olarak alınmıştır. 


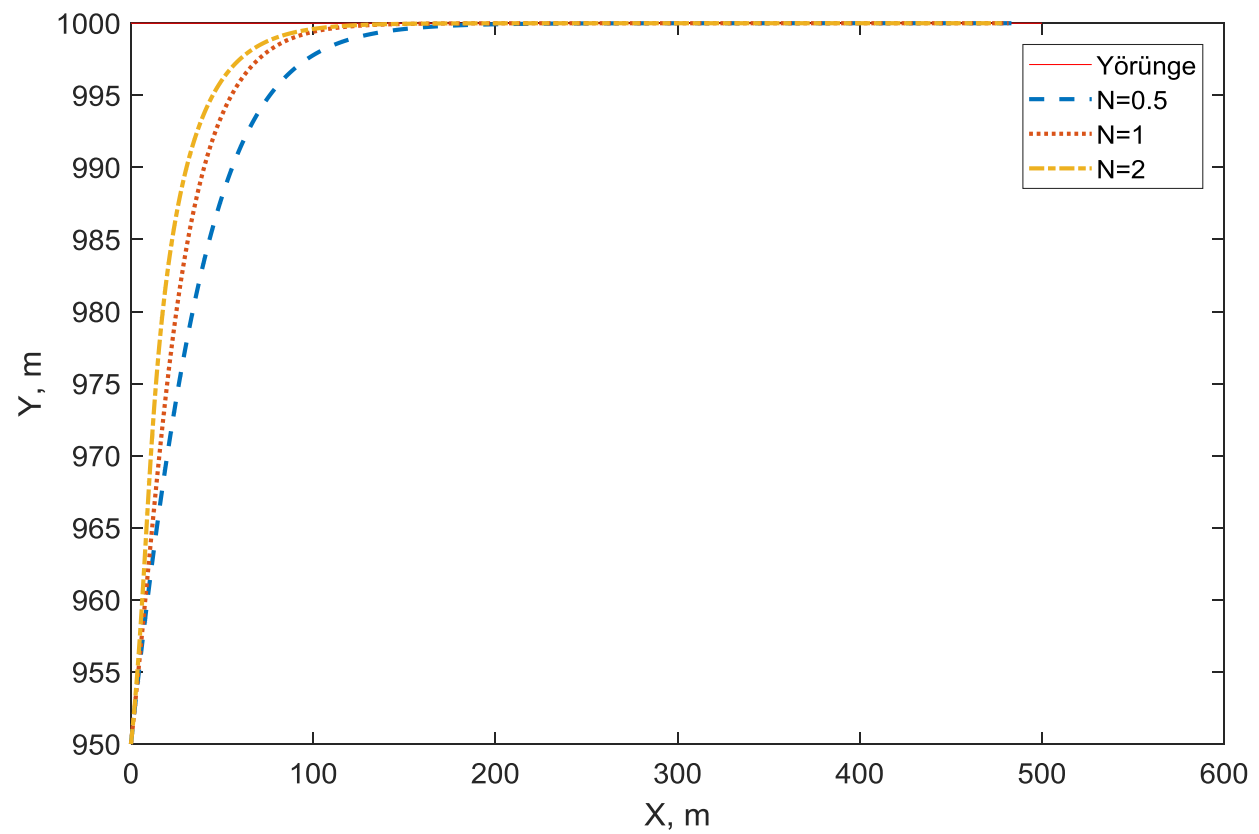

Şekil 3. Yörünge ve takip sonuçları
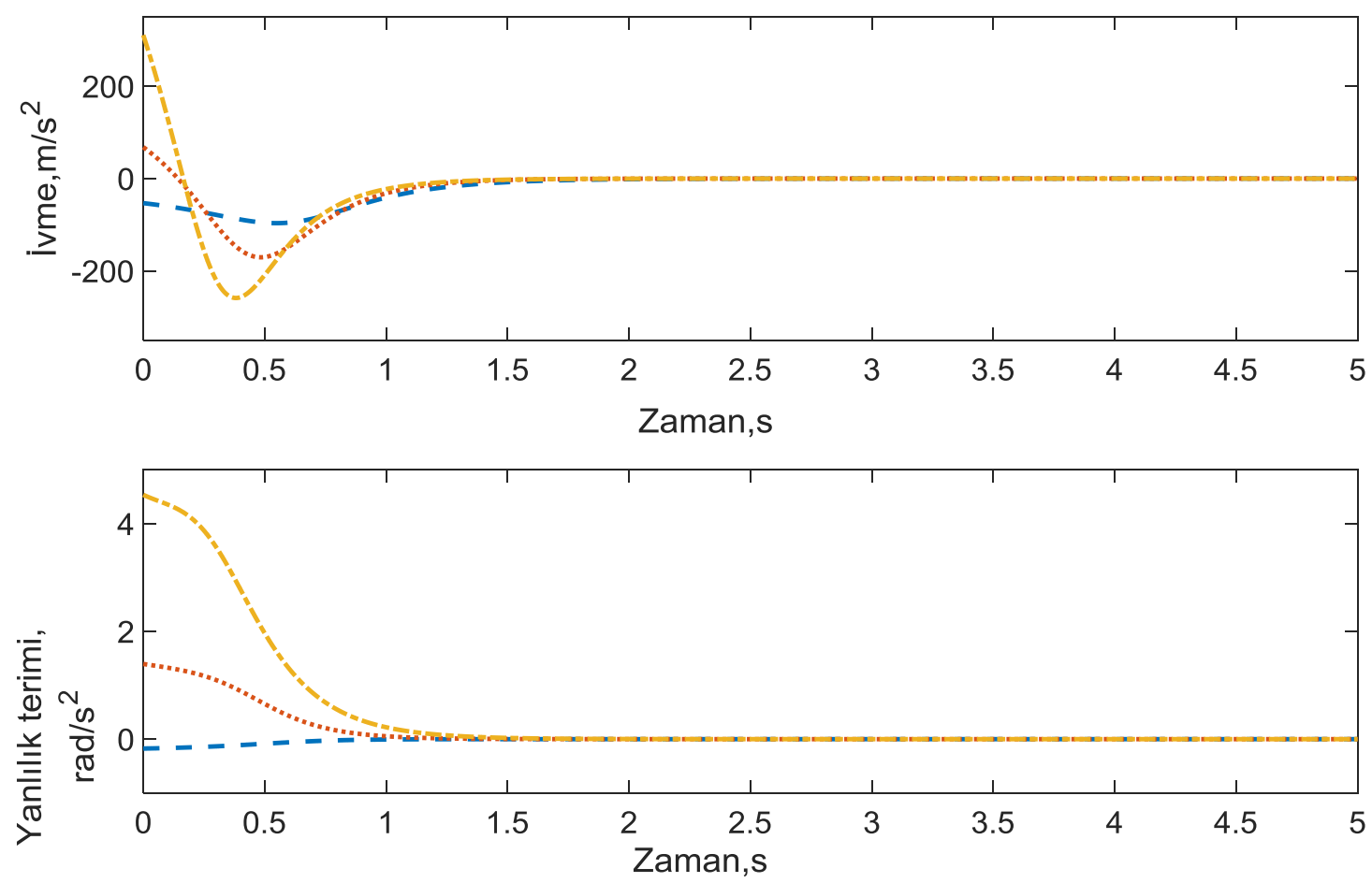

Şekil 4. İvme komutu ve yanlılık terimi

Şekil 3'te yörüngeleri görmek mümkündür. $N$ değeri arttıkça referans yörüngeye daha hızlı ulaşılmaktadır. Lakin bu kazancın geri ödemesi, ivme komutlarında kendini göstermektedir. Şekil 4'te ivme isteri ve yanlılık teriminin zamana bağlı değişimini görmek mümkündür. Şekil 5 'te düz yörüngeye olan takip mesafesi ve takip hatası sunulmuştur. $N$ değerinin artması hatanın sıfırlanma süresini azaltmaktadır. Ayrıca, düz bir yörünge için takip mesafesi farklı $N$ için farklı değerlere oturmaktadır ve $N$ azaldıkça takip mesafesi de azalmaktadır. 

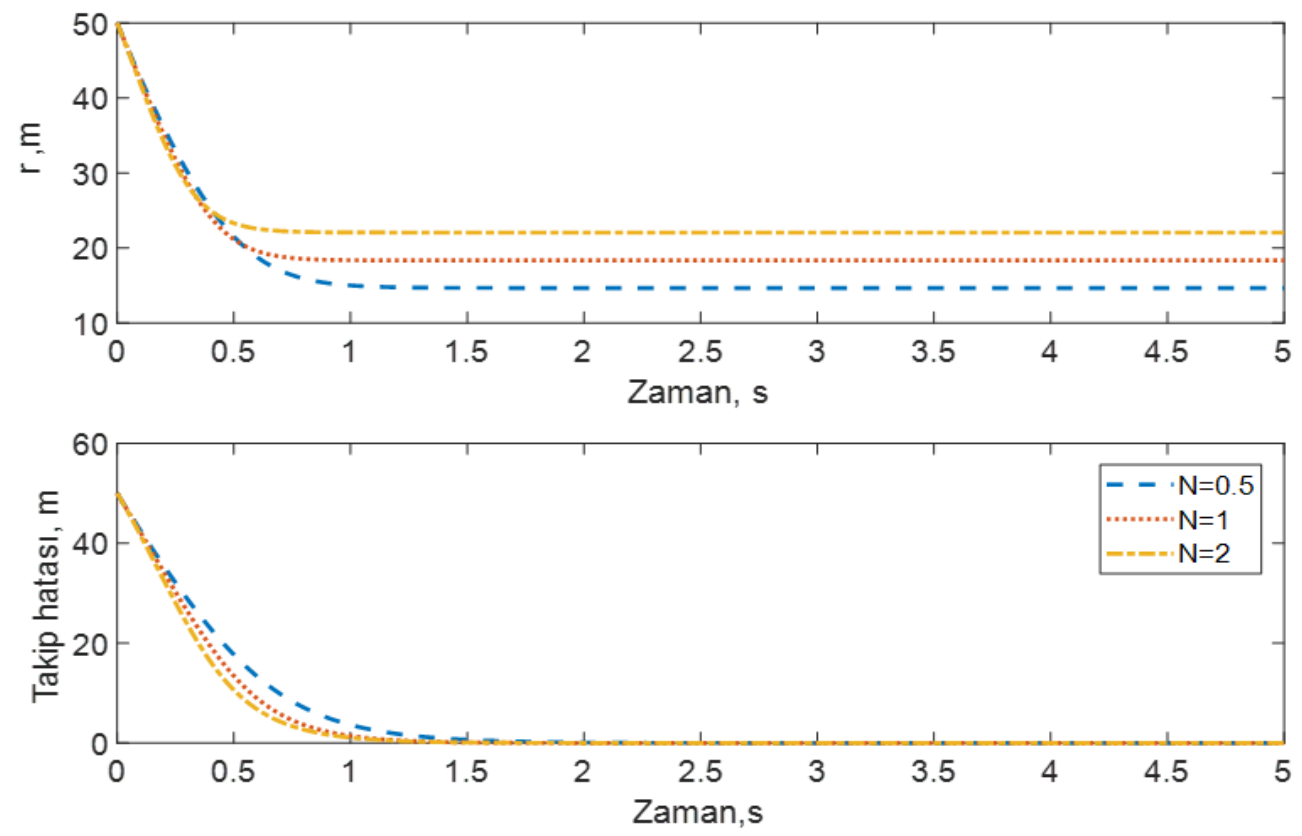

Şekil 5. Takip mesafesi ve yörünge takip hatası

\section{2 $r^{*}$ Değerine Bağlı Olarak Performans İncelemesi}

$\mathrm{Bu}$ çalışmada $r^{*}$ için farklı değerler seçilerek, bunun eğri bir yörünge takibindeki etkisi incelenmiştir. Ayrıca saf takip ile de karşılaştırma yapılmıştır.

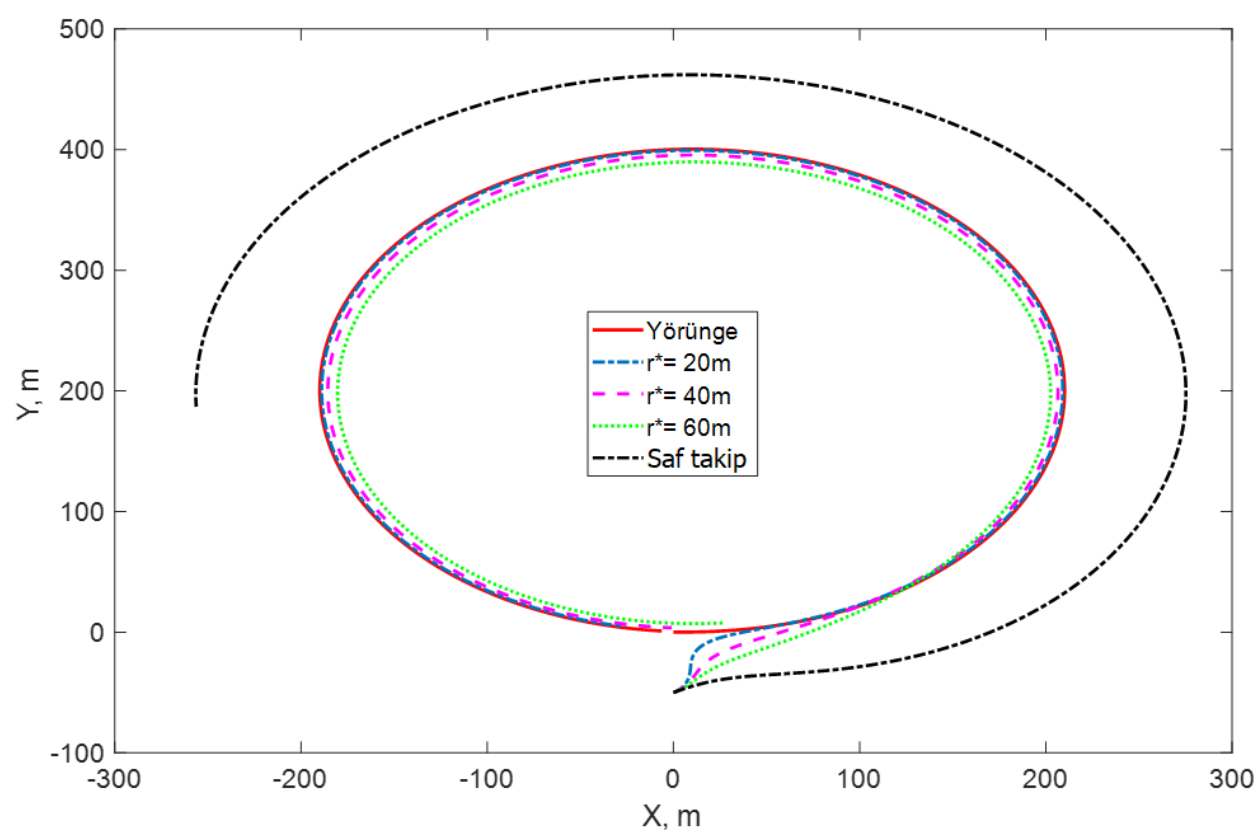

Şekil 6. Farkl1 $r^{*}$ için yörüngeler

Referans yörünge orijinden başlamaktadır. Takipçi ise [0, -50 m] noktasından hareketine başlamıştır ve $\gamma_{0}=30^{\circ}$ 'dir. $N$ değeri, 2 olarak alınmıştır. Şekil 5 incelendiğinde, $r^{*}$ değeri ne kadar düşük olursa o kadar yüksek başarım elde edildiği görülmektedir. Denklem 4'ün ise bu eğri yörüngeyi takip edebildiği söylenemez. 


\section{Sonuç ve Öneriler}

$\mathrm{Bu}$ çalışmada, yörünge takibi için geometrik yöntemler sınıfindan bir algoritma tasarımı anlatılmıştır. Sanal hedef takip kavramı kullanılarak, kuyruk takibi vasıtasıyla problem, bir füze güdüm problemine dönüştürülmüştür. Kuyruk takibi için geliştirilen güdüm yöntemi ise çarpma açısı kontrolünden esinlenilerek tasarlanmıştır. Önerilen yöntemin başarımı benzetim ortamında incelenmiş ve performans karşılaştırılması yapılmıştır. Ayrıca, performansı etkileyen unsurlar gösterilmiştir. Önerilen yörünge takip algoritmasının, yüksek işlem gücüne ihtiyaç duymaması, pratik bir uygulamaya hali hazırda sahip olması nedeniyle, mevcut ürünlerde kullanılan teknolojik altyapı ile uygulama alanı bulması beklenebilir.

\section{Kaynaklar}

[1]. Amidi, O., Thorpe, C., "Integrated Mobile Robot Control”, Mobile Robots V, 1991, 1388.

[2]. Ollero, A., Heredia, G., "Stability Analysis Of Mobile Robot Path Tracking", IEEE International Conference on Intelligent Robots and Systems, 1995, 3: 461-466.

[3]. Ratnoo, A., Hayoun, S.Y., Granot, A., Shima, T., "Path Following Using Trajectory Shaping Guidance", AIAA Journal of Guidance, Control, and Dynamics, 2015, 38(1): 106-116.

[4]. Zarchan, P., Tactical and Strategic Missile Guidance, $4^{\text {th }}$ ed., AIAA, Reston, 2002, 541-569.

[5]. Sujit, P.B., Saripalli, S., Sousa, B.J., "Unmanned Aerial Vehicle Path Following: A Survey and Analysis of Algorithms for Fixed-Wing Unmanned Aerial Vehicles”, IEEE Control Systems, 2014, 34(1): 42-59.

[6]. B. Rubí, R. Pérez, B. Morcego, "A Survey of Path Following Control Strategies for UAVs Focused on Quadrotors", Journal of Intelligent. Robotic Systems, 2019, 1-25.

[7]. Rafo, G.V., Ortega, M.G., Rubio, F.R., "Backstepping/Nonlinear H-infinity Control for Path Tracking of a Quadrotor Unmanned Aerial Vehicle", 2008, American Control Conference, 1(12), 3356- 3361.

[8]. Cichella, V., Choe, R., Mehdi, S.B., Xargay, E., Hovakimyan, N., Kaminer, I., Dobrokhodov, V., "A 3D Path-following Approach for a Multirotor UAV on so(3)", IFAC Proceedings, 2013, 46: 13-18.

[9]. Roza, A., Maggiore, M., "Path Following Controller for a Quadrotor Helicopter", American Control Conference, 2012, 4655-4660.

[10]. Nelson, D.R., Barber, D.B., McLain, T.W., Beard, R.W., "Vector Field Path Following for Miniature Air Vehicles", IEEE Transactions on Robotics, 2007, 23(3): 519-529.

[11]. Zhou, D., Schwager, M., "Vector Field Following for Quadrotors Using Differential Flatness" IEEE International Conference on Robotics and Automation, 2014, 6567-6572.

[12]. Micaelli, A., Samson, C., Robotique, P., Icare, P., "Trajectory Tracking for Unicycle-type and Two-Steering-Wheels Mobile Robots”, IFAC Proceedings Volumes, 1994, 27: 249-256.

[13]. Medagoda, E.D.B., Gibbens, P.W., "Synthetic-Waypoint Guidance Algorithm for Following a Desired Flight Trajectory", AIAA Journal of Guidance, Control, and Dynamics, 2010, 33(2): 601-606.

[14]. Erer, K.S., Tekin, R., Özgören, M.K., "Biased Proportional Navigation with Exponentially Decaying Error for Impact Angle Control and Path Following", 24th Mediterranean Conference on Control and Automation, 2016, IEEE Publ., Piscataway, NJ, 238-243.

[15]. Kim, B.S., Lee, J.G., Hyung, S., Han, H.S., "Biased PNG Law for Impact with Angular Constraint", IEEE Transactions on Aerospace and Electronic Systems, 34(1): 277-288.

[16]. Erer, K.S., Merttopçuoglu, O., "Indirect Impact-Angle-Control Against Stationary Targets Using Biased Pure Proportional Navigation”, AIAA Journal of Guidance, Control, and Dynamics, 2012, 35(2): 700-704. 